\title{
ANOMALOUS CHROMOSOME BEHAVIOUR IN THE GERM LINE OF SCHISTOCERCA GREGARIA
}

\author{
B. JOHN and B. NAYLOR \\ A.R.C. Unit of Biometrical Genetics, Genetics Department, \\ Birmingham University
}

\section{INTRODUCTION}

Received I.iii.6r

ONE of the standard methods of analysing biological normality is by the study of anomaly. This method is not without limitations; in particular its successful application depends upon correctly relating the abnormal to the normal. But it can often provide crucial information which is unobtainable in any other way. For example a whole series of chromosome anomalies, recently summarised and extended by Brown and Zohary (1955), collectively provide critical evidence for the chiasmatype hypothesis.

The study of chromosome anomalies is especially instructive because such anomalies may sometimes be the starting point for evolutionary change. Not only does their study lead to a better understanding of the mechanical properties of the chromosomes but it often reveals the potentialities of a chromosome complement for change.

\section{MATERIAL AND TECHNIQUE}

All observations were made on 24 male sibs of the desert locust Schistocerca gregaria (Forskål). These were derived from a mating between two isolated members of a stock culture maintained by the Anti-Locust Research Centre. This culture was started in 1946 from egg pods obtained in British Somaliland. In I953 and 1957 two additional batches of wild adults were added to the stock and throughout the life of the culture the locusts have been kept in conditions of maximum crowding. There are approximately four generations per annum and at each generation there is a $60-80$ per cent. mortality prior to mating. Numbers are even further reduced in supplying specimens for research purposes and the culture is then maintained from the survivors.

Following vivisection in insect saline the testis follicles were freed from the investing fat body, fixed in 1 : 3 acetic alcohol and subsequently squashed in acetic orcein.

\section{THE NORMAL COMPLEMENT}

Although several workers have previously used males of this species for cytological purposes little attention has been paid to the overall properties of the standard complement. For this reason it seems worth summarising these before dealing with the anomalies:

(i) The chromosome complement of the male in this species is $2 n=22+\mathrm{X}$ (plate I, figs. I-6). The autosomes can be divided into three groups on the basis of their relative sizes; these 
include three pairs of large, five pairs of medium and three pairs of small homologues (plate I, figs. 3-5). The X chromosome is probably the second largest in size (table $\mathrm{I}$ ).

(ii) All twenty-three chromosomes are acrocentric (plate I, figs. 2-4).

(iii) The spindle tends to be hollow in all cells of the germ line. This tendency is not, however, absolute for at mitosis and especially at meiosis the smaller autosomes and the univalent sex chromosome frequently lie in the centre of the spindle (plate I, figs. 3, 4, 6 and I 3 ). This agrees with their relative size and valency relationships respectively ( $c f$. Lewis and Scudder, I958).

TABLE I

Mean linear dimensions of the basic complement with their standard deviations

\begin{tabular}{|c|c|c|c|c|c|c|c|c|c|c|c|c|}
\hline \multirow{2}{*}{ Stage } & \multicolumn{12}{|c|}{ Mean length in micra } \\
\hline & $\mathrm{L}_{\mathbf{I}}$ & $\mathrm{L}_{2}$ & $\mathrm{~L}_{3}$ & $\mathrm{M}_{4}$ & $\mathrm{M}_{5}$ & M6 & $\mathrm{M}_{7}$ & M8 & $\mathrm{S}_{9}$ & Sio & $S_{11}$ & $\mathbf{X}$ \\
\hline $\begin{array}{l}\text { Mitotic metaphase } \\
\text { (mean from } 16 \text { nuclei) }\end{array}$ & $\begin{array}{l}7 \cdot 4 \\
\pm \\
0 \cdot 1\end{array}$ & $\begin{array}{l}6.7 \\
\pm \\
0.2\end{array}$ & $\begin{array}{l}5 \cdot 8 \\
\pm \\
0.1\end{array}$ & $\begin{array}{l}4.9 \\
\pm \\
0^{\circ} \cdot 1\end{array}$ & $\begin{array}{l}4.3 \\
\pm \\
0.1\end{array}$ & $\begin{array}{l}3.9 \\
\pm \\
0.1\end{array}$ & $\begin{array}{l}3.6 \\
\pm \\
0.1\end{array}$ & $\begin{array}{l}3 \cdot 3 \\
\pm \\
0 \cdot 1\end{array}$ & $\begin{array}{l}2 \cdot 4 \\
\pm \\
0.1\end{array}$ & $\begin{array}{l}2 \cdot 1 \\
\pm \\
0 \cdot 1\end{array}$ & $\begin{array}{l}1 \cdot 9 \\
\pm \\
0 \cdot 1\end{array}$ & $\begin{array}{l}6 \cdot 7 \\
\pm \\
0 \cdot 2\end{array}$ \\
\hline $\begin{array}{l}\text { Pachytene (mean from } \\
25 \text { nuclei) }\end{array}$ & $\begin{array}{c}71 \cdot 5 \\
\pm \\
2 \cdot 6\end{array}$ & $\begin{array}{c}58 \cdot 8 \\
\pm \\
2 \cdot 7\end{array}$ & $\begin{array}{c}47.7 \\
\pm \\
2 \cdot 1\end{array}$ & $\begin{array}{c}39.9 \\
\pm \\
\pm \\
1 \cdot 8\end{array}$ & $\begin{array}{c}30 \cdot 8 \\
\pm \\
I \cdot 2\end{array}$ & $\begin{array}{c}26 \cdot 6 \\
\pm \\
1 \cdot 1\end{array}$ & $\begin{array}{c}24.6 \\
\pm \\
1 \cdot 0\end{array}$ & $\begin{array}{c}21 \cdot 8 \\
\pm \\
1 \cdot 0\end{array}$ & $\begin{array}{c}15.7 \\
\pm \\
1.0\end{array}$ & $\begin{array}{c}14 \cdot 2 \\
\pm \\
1 \cdot 0\end{array}$ & $\begin{array}{c}12.4 \\
\pm \\
1.0\end{array}$ & $\begin{array}{c}14 \cdot 6 \\
\pm \\
0 \cdot 3\end{array}$ \\
\hline
\end{tabular}

(iv) The unpaired $\mathrm{X}$ chromosome is allocyclic with respect to the autosomes. It is negatively heteropycnotic at mitosis (plate I, figs. I and 2) and at first metaphase of meiosis (plate I, fig. 6) and positively heteropycnotic at pre-meiotic interphase, at first (plate I, fig. 5) and second prophase of meiosis and in the first post-meiotic interphase. At metaphase- $\mathrm{I}$ the $\mathrm{X}$ is rather variable in appearance. Usually it is completely negatively heteropycnotic. But in other cases either the centric end alone (compare Chorthippus; John, Lewis and Henderson, 1960) or infrequently both ends (compare (Pyrgomorpha; Lewis and John, 1959) of the $\mathrm{X}$ retain their prophasic appearance.

(v) The autosomes, on the other hand, show a differential behaviour within themselves during pachytene when their centric end segments condense in advance of the main chromosome thread (plate I, fig. 5; plate II, fig. Io). This, like the tendency for the development of a hollow spindle, is a property which is widely distributed in orthopteran species. 


\section{THE ANOMALIES}

Five types of meiotic anomaly were observed. These were as follows :

(i) Chromatid bridge formation at AI.

(ii) The occurrence of achromatic gaps at pachytene-diplotene.

(iii) Univalent formation.

(iv) Multiple formation by interchange.

(v) Multivalent formation following mitotic non-disjunction.

Anomalies (i) and (ii) were found in the same individual (No. 3) and (i) was also found in individual No. I. The remainder occurred in distinct individuals.

The first two of these need little discussion. The chromatid bridges were of the type we have recently discovered in Chorthippus brunneus (John, Lewis and Henderson, 1960) involving an interstitial association between sister chromatids in one of the long chromosomes (plate I, fig. 7). Such bridges were found in single anaphase cells of two individuals, Nos. I and 3 respectively; achromatic gap formation also occurred in No. 3. Here 48 per cent. of the pachytene cells examined included chromosomes with marked gaps (plate II, figs. 8 and 9). Seventy per cent. of the affected cells had two such chromosomes per nucleus and the remainder one. These gaps occurred in either the long or medium chromosomes only and involved both chromatids of either one or both homologues of a bivalent. In the latter case corresponding loci were always concerned. Diplotene cells with similar gaps were also found in this individual, but were not evident at the later meiotic stages; neither did they lead to any apparent subsequent abnormality. Comparable achromatic gaps were seen in other individuals of this sibship but here their frequency never exceeded I per cent. We have also seen such exceptional behaviour in Chorthippus brunneus.

Neither of these two anomalies gives us any useful information about the inherent properties of the complement because, as yet, we do not understand their nature. But the individual with univalents tells us something about the control of bivalent formation and the two remaining anomalies give us some insight into the principles which govern karyotyptic change.

\section{THE CONTROL OF BIVALENT FORMATION}

Univalents were recorded in five of the individuals examined. In four of these their frequency did not exceed 2 per cent. but in individual (NI) I4 per cent. of the 4I 5 meiotic cells scored contained either one or, less usually, two pairs of univalents. These occurred predominantly in the $\mathrm{S}_{9}-\mathrm{S}_{\text {I I }}$ classes, less frequently in the M8 chromosomes (plate II, figs. IO-I2). The occurrence of univalents in this individual raises two points of particular interest. First, to what extent are the chiasma 
frequencies of the three size classes of chromosomes affected in the cells with univalents? Secondly, does the pattern of chiasma frequency differ in the normal nuclei of this individual as compared with normal cells in unaffected sibs?

TABLE 2

Comparison of chiasma frequency distributions in 55 cells with and without univalents in individual $\mathcal{N}_{I}$

\begin{tabular}{|c|c|c|c|c|c|c|}
\hline \multirow{2}{*}{\multicolumn{3}{|c|}{ Chromosome size group }} & \multicolumn{2}{|c|}{ Mean cell chiasma frequency } & \multirow{2}{*}{$c$} & \multirow{2}{*}{$\mathbf{P}$} \\
\hline & & & \multirow{2}{*}{$\begin{array}{l}\begin{array}{l}\text { Cells with } \\
\text { univalents }\end{array} \\
6 \cdot 47 \pm 0 \cdot 15\end{array}$} & Normal cells & & \\
\hline Long $\left(\mathrm{L}_{1}-\mathrm{L}_{3}\right)$. & . & 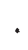 & & $6 \cdot 86 \pm 0 \cdot 12$ & $1 \cdot 99$ & $0.05-0.02$ \\
\hline Medium (M4-M8) & . & - & $6 \cdot 19 \pm 0 \cdot 17$ & $7 \cdot 53 \pm 0 \cdot 15$ & $2 \cdot 71$ & $0.01-0.001$ \\
\hline Short $\left(\mathrm{S}_{9}-\mathrm{S}_{11}\right)$ & - & - & $2 \cdot 15 \pm 0 \cdot 06$ & $3 \cdot 00 \pm 0 \cdot 00$ & $15 \cdot 68$ & $\ll 0.001$ \\
\hline
\end{tabular}

To resolve the first of these questions a total of I ro meiotic nuclei were scored in the anomalous individual; 55 of these contained univalents and 55 were normal. In each nucleus the chiasma frequency of the three size classes of chromosomes were treated separately and the data is summarised in table 2. A $c$ test for the differences in means between cells with and without univalents is given in column three of this table and in all cases the differences are significant.

TABLE 3

Analysis of variance of the difference between mean chiasma frequencies in normal cells of the anomalous individual $(\mathrm{Na})$ and normal cells of nine sibs $\left(\mathcal{N}_{2-I O}\right)$. Fifty-five cells were scored in each of the ten individuals.

\begin{tabular}{|c|c|c|c|c|}
\hline Item & & $\mathbf{N}$ & M.S. & $\mathbf{P}$ \\
\hline I. $\mathrm{Na} V \mathrm{~N} 2-10$ & . & 1 & $90 \cdot 69$ & $0.20-0.10$ \\
\hline 2. Between $\mathrm{N}_{2-10}$ & . & 8 & $27 \cdot 88$ & $<0.001$ \\
\hline 3. Error (between cells) & . & $54^{\circ}$ & $2 \cdot 85$ & $\ldots$ \\
\hline
\end{tabular}

The second question was resolved by comparing the difference between the mean chiasma frequency in 55 normal cells of the anomalous individual (NI) with that of 55 cells from each of nine normal sibs of the same age group $\left(\mathrm{N}_{2}-\mathrm{N}_{1} \mathrm{O}\right)$ giving a total of $55^{\circ}$ observations and thus 549 degrees of freedom. Of these one goes to the comparison between $\mathrm{N}_{\mathrm{I}}$ and $\mathrm{N}_{2}-\mathrm{IO}, 8$ are concerned with the variation between the 9 normal sibs leaving $54^{\circ}$ for the error item (table 3 ). This comparison shows that the 9 normal sibs differ amongst themselves as far as chiasma frequency is concerned (text-fig. I). Because 


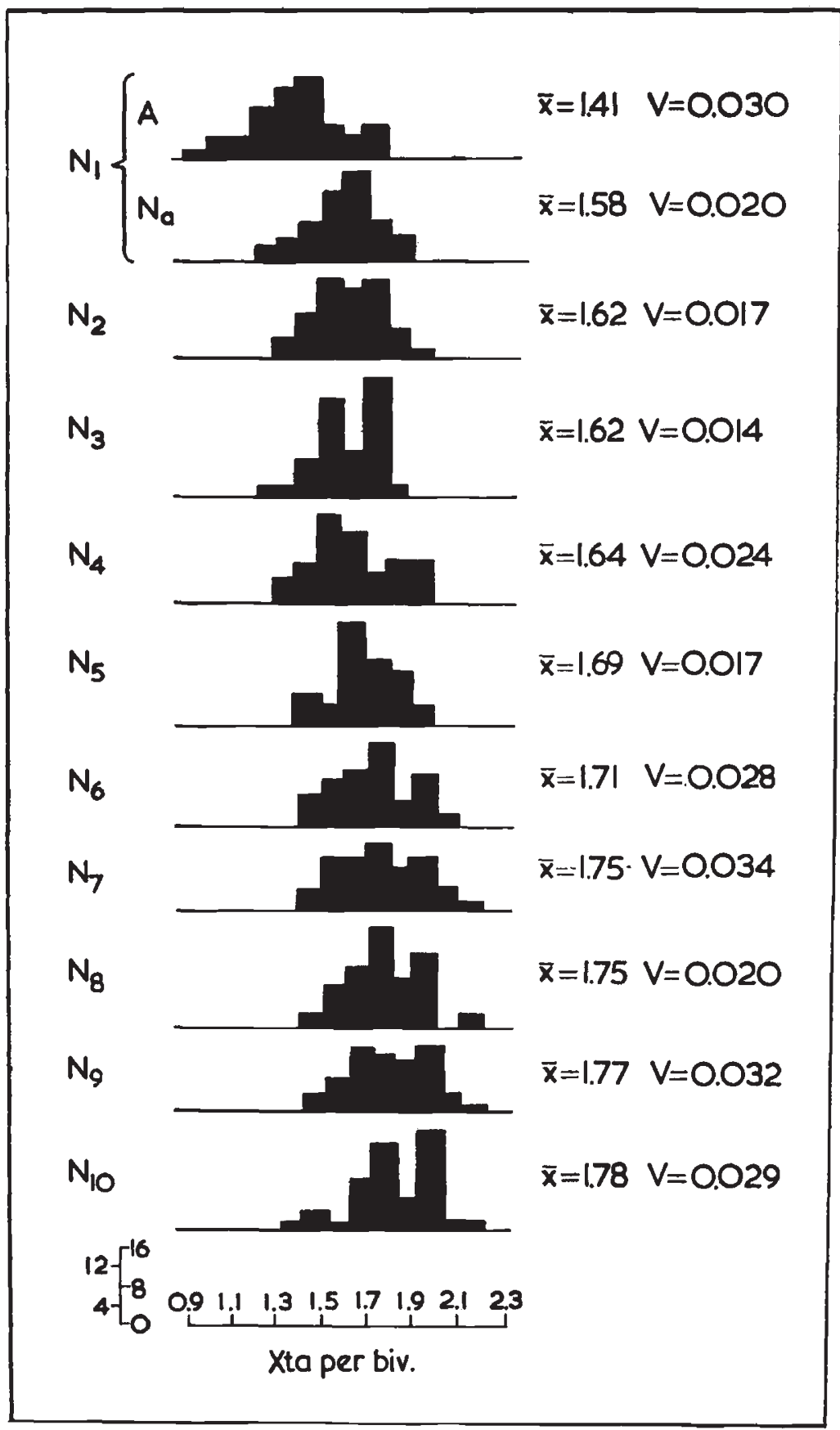

Text-FIG. 1.-Distribution of chiasma frequencies in 55 cells with univalents (A) and 55 normal ( $\mathrm{Na}$ ) cells of the asynaptic individual (NI) and in 55 cells from each of nine normal sibs $\left(\mathrm{N}_{2}-\mathrm{N}_{10} \mathrm{O}\right.$. 
of this the appropriate test of significance for the differences between the normal nuclei of the anomalous individual and that of the pooled 9 normal sibs depends upon a comparison between the first and second item mean squares in table 3. Such a comparison demonstrates that

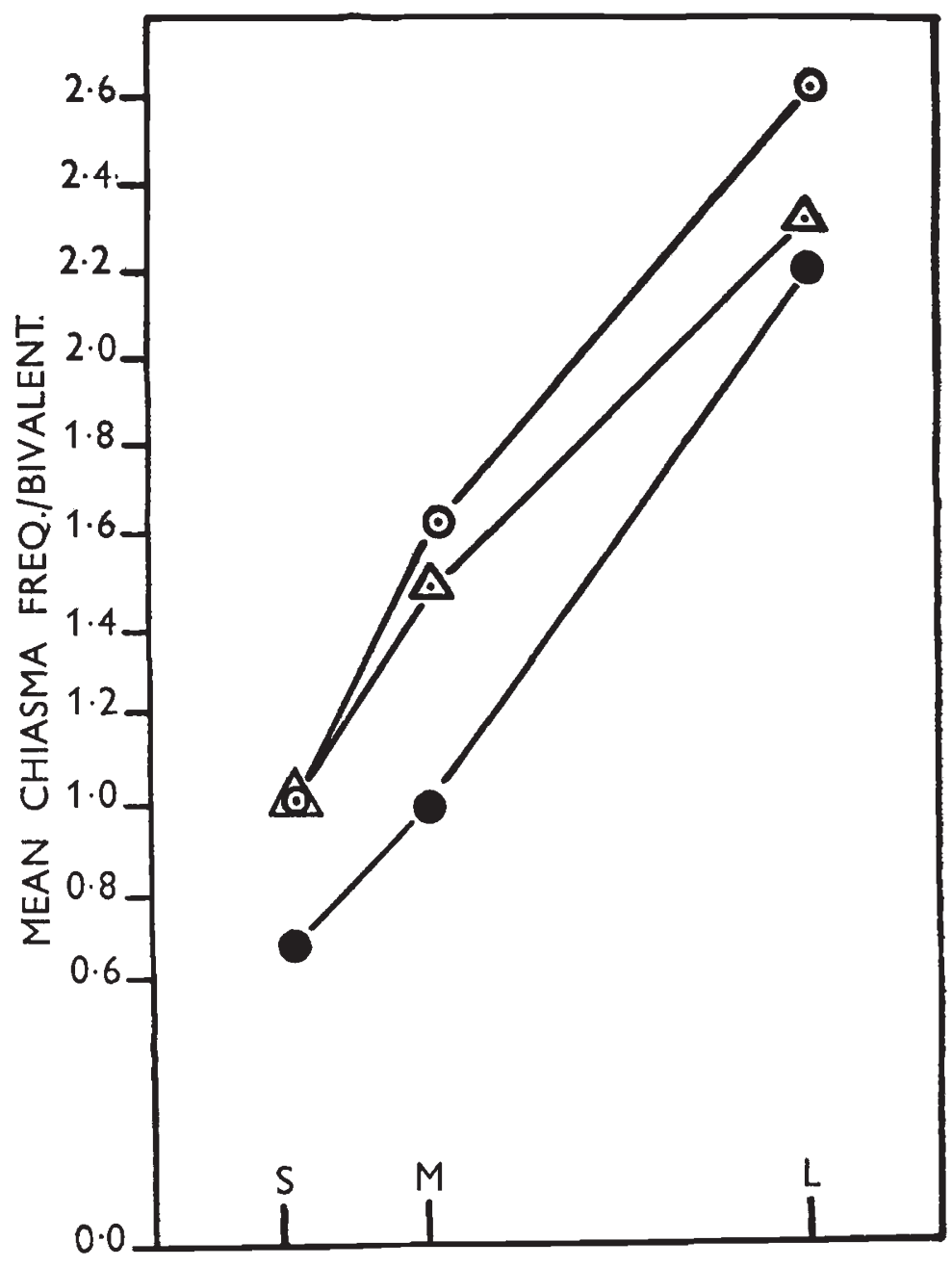

\section{CHROMOSOME SIZE}

TEXT-FIg. 2.-Mean chiasma frequency per bivalent type in each of the three size classes of chromosomes taken from nine normal individuals, $\mathrm{N}_{2}-\mathrm{N}_{1} \mathrm{O},(\odot)$ and from asynaptic cells, $\mathrm{A},(\odot)$ and normal cells, $\mathrm{Na},(\Delta)$ of an asynaptic individual of the same age and sibship. The chromosome size relationships have been calculated from mitotic chromosome lengths.

the mean chiasma frequency of these two classes of normal nuclei does not differ significantly (text-fig. 2).

Now univalent formation in a diploid species may result from a variety of causes, both genotypic and environmental, and the precise cause is not always easily determined. In a first analysis, however, 
one must attempt to distinguish between true failure of pairing (asynapsis, e.g. Ross et al., I96o) and chiasma failure following successful pairing (desynapsis). This distinction is one that has not always been, or could be, correctly made. Indeed in so-called " asynaptic" maize pachytene pairing looks complete (Beadle, I933) so that here univalent formation is a consequence of desynapsis. The same appears to be true in many " asynaptic" plants ( $c f$. Li, Pao and Li, I 945).

Such behaviour forces us to admit that while pairing is a necessary pre-requisite for exchange it is not in itself a sufficient cause for crossing over and that there is a need to distinguish between effective and noneffective pairing. Thus Darlington and Haque (1955) described an abnormal plant of Allium ascolonicum in which, while chromosome pairing was complete, a large proportion of the p.m.c.'s were desynaptic. The marked decrease in the number of chiasmata in these cells was explained by a reduction of coiling to about one-half that normally found. This then is a case in point; it would appear that it is a failure in coiling, not pairing, which is responsible for the decreased chiasma formation and hence desynapsis. Clearly there are factors which can impede the formation of chiasmata without exerting any visible effect on pairing.

In the case under consideration univalents were present at pachytene (plate II, fig. Io). This evidence is not as compelling as it might be because the small chromosomes are frequently in advance of the remainder of the complement with respect to chromosome repulsion and the opening out of the pachytene bivalent (plate I, fig. 5; plate II, fig. 10). However, further support for a possible asynaptic mode of origin of the univalents in this case comes from some observations recently made in our laboratory on the effect of high temperature treatment on chiasma formation in $S$. gregaria. These observations are as yet incomplete but Mr S. A. Henderson, who is carrying out the work, allows us to make the following significant points:

(i) In the heat treated specimens varying numbers of univalents are present but the small chromosomes are generally first to be affected. Univalent formation in this case can definitely be correlated with a failure of pairing and this applies to all classes of chromosomes. In extreme cases there may be total asynapsis.

(ii) Where partial asynapsis occurs the chiasma frequency of the longest chromosomes is significantly reduced and is accompanied by an increase in the differential distance. In extreme cases the chiasmata are distally localised.

Asynapsis is also supported by the fact that the univalents in our case show no tendency to secondary association ( $c f$. Thermann, r95 I ; Riley and Chapman, I957).

On the other hand we have the evidence that there is a general reduction in chiasma frequency in the univalent containing cells. As a 
minimum hypothesis it would appear more likely that both univalent production and chiasma frequency reduction are governed by the same cause - a failure of effective pairing. From a cytological point of view, however, those homologues which succeed in forming bivalents in the univalent containing cells appear to be completely paired; chromosome contraction also looks normal (plate II, fig. Io). Obviously, however, although pachytene behaviour looks normal it must be abnormal in some way since there is a significant decrease in chiasma frequency for all chromosome classes irrespective of whether or no these classes are represented as univalents (table 2). It is of course possible that partial pairing by attraction is extended by torsion forces (see McClintock, 1933) with only the former leading to effective pairing.

Our provisional conclusion then is that we are dealing here with a case of asynapsis due to an absence of pairing or a reduction in its efficiency. The former is expressed as univalent production in the smallest chromosomes and the latter in a reduced chiasma frequency in those which succeed in forming bivalents. But these processes have involved only 14 per cent. of the cells analysed. The remaining cells are all normal in pairing behaviour and do not differ significantly in their chiasma frequency from that of normal sibs. It is interesting to note, however, that the mean chiasma frequency of these normal cells is halfway between that of the univalent containing cells and the average mean of 9 normal sibs (text-fig. I). It would appear, therefore, that the cells with univalents are merely an extreme expression of a continuous distribution about a lower mean, but since one chiasma is the minimum compatible with bivalent production a pronounced visible distinction necessarily arises between those cells which do and those which do not contain univalents. This distinction can be treated as a meristic difference because the presence of univalents is not consistent with regular segregation.

This situation provides an instructive comparison to that described by Rees (1957) in Locusta migratoria. Here the same number of chromosomes are present as in Schistocerca and a similar range of chromosome size occurs within the complement. In one individual Rees found extensive univalent formation with the highest proportion of univalents in the long and long medium chromosomes. Clearly the causes of reduced chiasma frequency are different in these two cases. In the one, Schistocerca, the reduction is general affecting all the chromosomes, though not equally so, while in the other, Locusta, it is differential affecting the long chromosomes preferentially.

Although he did not analyse pachytene cells of Locusta in detail, Rees (personal communication) is of the opinion that in his case unpaired chromosomes, or chromosome regions were not present to any significant extent at this stage. It is possible then to reconcile these two divergent instances on the assumption that Rees was dealing with a case of desynapsis. In Neuroptera Suomalainen (1952) has found that 
pachytene pairing is complete but that nevertheless chiasmata are localised distally. Significantly, however, polarisation of the leptotene-zygotene nuclei determines that pairing begins at the chromosome ends. Here it would appear that chromosome segments which pair first are preferred in chiasma formation presumably because they reach the appropriate stage for exchange before the later paired regions. In at least some instances of asynapsis or desynapsis there are definite indications that general disturbances of timing relations are involved (Rees, 1952; Darlington and Haque, I955). Certainly alterations in the time available for pairing appears to be one of the prime variables of meiosis (Darlington, 1940). We have already commented on the fact that in Schistocerca the small chromosomes are frequently in advance of the remainder in their prophase behaviour. Perhaps in complements with such marked size differences chromosomes which, by virtue of their small size, pair first are also preferred in chiasma formation. Under these circumstances if the chiasma frequency falls below its normal range the small chromosomes will be at an immediate advantage in forming chiasmata.

However these contrasting observations are ultimately resolved they serve to emphasise the complexity of the processes involved in the control and maintenance of bivalent development.

\section{THE BASIS OF KARYOTYPE CHANGE}

In individual No. 2 a cell was found containing nine bivalents, one trivalent and one univalent in addition to the unpaired $\mathrm{X}$ (plate II, fig. 13). Such an association would follow a reciprocal translocation between the $\mathrm{L}_{3}$ and $\mathrm{M} 8$ chromosomes in which the interchange has involved the terminal segment of the short arm of the $\mathrm{L}_{3}$ and the distal portion of the long arm of M8 (text-fig. 3). A single cell containing ten bivalents, one quadrivalent and the sex univalent occurred in individual No. 9 (plate II, fig. I4). Quadrivalent formation in this instance must have been the consequence of simultaneous non-disjunction in both homologues of one of the $\mathrm{L}$ chromosomes at the last pre-meiotic mitosis.

Reorganisation of the chromosome complement during evolution depends upon two events: first, the occurrence of both structural and numerical anomalies and secondly, the subsequent survival of these. To a large extent it has been assumed, explicitly or implicitly, that all types of chromosome mutation probably occur in all organisms at low frequencies but that few survive to be selectively incorporated into the genetic system. While it is debatable to what extent this statement is generally applicable there can be little doubt that, as far as orthopterans are concerned, the evidence, with one qualification, favours acceptance of this idea. This qualification depends upon the fact that while the chromosome system may have attained stability under particular breeding conditions it may become unstable if the breeding system departs from its characteristic structure ( $c f$. Rees, 


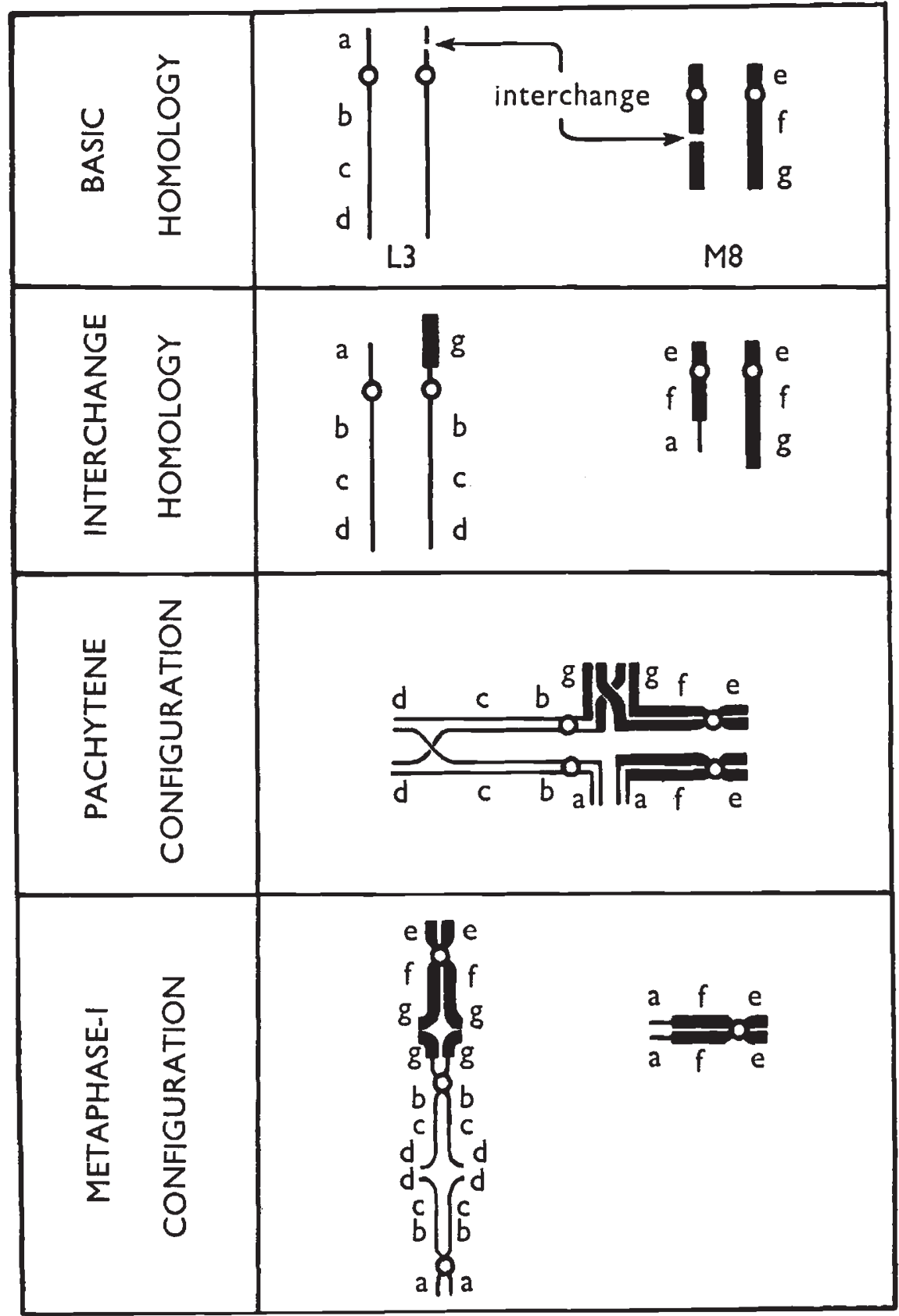

TEXT-FIG. 3.-Derivation of the L3-M8 interchange association of three (cf. plate II, fig. 13). 
1955; Lewis and John, 1959). Indeed we suggest that the situation observed in this single sibship is not fortuitous and that these several anomalies all result from a breakdown of normal genotypic control and must be regarded as instances of correlated instability. This instability in turn is a reflection of the unusual breeding structure of the culture from which the sibship was derived.

With this qualification in mind there is no doubt that most of the major classes of structural and numerical changes have been, or can be, demonstrated to occur spontaneously in the germ line of orthopterans (White, 1959; Lewis and John, unpublished). In this present account we can add isolated examples of aneuploidy and interchange. There is, however, equally no doubt that few of these, including our two instances, can be expected to survive. There are of course good reasons why this should be so. Chromosome behaviour is normally self-regulating in the sense that anomalies, because they lead to mechanical disturbance at meiosis, necessarily produce a reduction in fertility.

Structural and numerical hybrids may, therefore, produce segregational sterility because of the unbalance of their meiotic products. But the extent to which they do so is largely a reflection of their own genetic organisation, depending in particular on the cyto-morphological characteristics of their chromosomes and more especially upon their properties of chiasma formation. Any mechanism which determines the formation of balanced gametes or which, in animals, leads to the incapacity of unbalanced ones, will favour the survival of the new chromosome type. How this operates is particularly well illustrated by the Diptera which thus far appear to be unique among animals in the frequency with which paracentric inversions occur in wild populations. Here there are several mechanical peculiarities of the meiotic system which facilitate a toleration for this particular category of change (Brito da Cunha, ig6o).

The inherent organisation of the karyotype thus provides for its own change by facilitating or limiting both the types of chromosome reorganisation which can occur and those which can be expected to establish themselves. The case against the establishment of aneuploid types is well known and recently we have considered in detail the special problems which limit the survival of interchange multiples in complements which, like Schistocerca, are completely acrocentric in organisation (John and Lewis, 1960).

\section{SUMMARY}

I. A series of five types of chromosome anomalies have been found in the meiotic cells of a single sibship of the desert locust Schistocerca gregaria.

2. Three of these involved only single cells in distinct individuals including one instance of both interchange and pre-meiotic non-disjunction and two cases of chromatid-bridge formation at AI. 
3. The remaining two anomalies were more extensive, though both were confined to single individuals. One of these took the form of peculiar achromatic gaps at prophase I in conjunction with Anaphase-I chromatid bridge formation. The other involved chromosome asynapsis.

4. We are inclined to interpret these several anomalies as correlated changes in nuclear phenotype dependent upon the production of a novel genotype within the sibship. This is perhaps determined by the inbred nature of the culture from which the sibship was derived.

5. The anomalies themselves have no apparent future in heredity or evolution though of course genetically identical cells of normal phenotype may survive to perpetuate their genetic basis.

Acknowledgments.-We are grateful to Professor K. Mather for critical reading of the manuscript. We also wish to thank Mr Phillip Hunter-Jones of the Anti-Locust Research Centre for supplying the material.

\section{REFERENCES}

BEADLE, G. W. 1933. Further studies in asynaptic maize. Cytologia, 4, 269-287. BRITO DA GUHNA, A. 196o. Chromosomal variation and adaptation in insects. Ann. Rev. Entomol., 5, 85-1 10.

BROWN, s. W., AND zOHARY, D. 1955. The relationship of chiasmata and crossingover in Lilium formosanum. Genetics, $40,850-873$.

Darlington, G. D. I940. Prime variables of Meiosis. Biol. Rev., 15, 307-322.

Darlington, G. D., AND haque, A. 1955. The timing of mitosis and meiosis in Allium ascolonicum. Heredity, 9, 117-127.

John, B., AND LEWIs, K. R. Ig6o. Chromosome structure in Periplaneta americana. Heredity, $15,47-54$.

JOHN, B., LEWIS, K. R., AND heNDERson, s. A. I 960 . Chromosome abnormalities in a wild population of Chorthippus brunneus. Chromosoma, II, 1-20.

LEWIS, K. R., AND JOHN, B. 1959. Breakdown and restoration of chromosome stability following inbreeding in a locust. Chromosoma, 10, 589-618.

LEWIS, K. R., AND SGUDDER, G. G. E. 1958. The chromosomes of Dicranocephalus Cytologia, 23, 92-104.

LI, H. W., PAO, W. K., AND LI, C. H. 1945. Desynapsis in the common wheat. Amer. 7. Bot., 32, 92-101.

MCGLINTOGK, B. 1933. The association of non-homologous parts of chromosomes in the mid-prophase of meiosis in Zea mays. Zeit. Zell. u. Mikr. Anat., 21, 294328.

REES, H. 1952. Asynapsis and spontaneous chromosome breakage in Scilla. Heredity, $6,89-97$.

REES, H. 1955. Genotypic control of chromosome behaviour in rye. I. Inbred lines. Heredity, 9, 93-1 16.

REES, H. 1957. Distribution of chiasmata in an asynaptic locust. Nature, $180,589$. RILEY, R., AND ChAPMAN, v. 1957. Haploids and polyhaploids in Egilops and Triticum. Heredity, $11,195-207$.

ross, J. G., SANDERs, M. E., AND FranzKe, G. J. 196o. Asynapsis in Sorghum. Hereditas, $46,570-580$.

SUOMALAINEN, H. о. T. Localisation of chiasmata in the light of observations on the spermatogenesis of certain Neuroptera. Ann. Zool. Soc. Zool. Bot. Fenn. vanamo, 15, I-104.

THERMAN, E. 1951. Somatic and secondary pairing in Ornithogalum. Heredity, 5, 253-269.

WHITE, M. J. D. 1959. Speciation in animals. Aust. J. Sci., 22, 32-39. 


\section{Plate I}

All acetic orcein squash preparations.

FIG. I.-Mitotic prophase; $\mathrm{X}$ to right of autosomes and undercondensed. $\times{ }_{15} 500$.

FIG. 2.-Mitotic metaphase; negatively heteropycnotic $\mathrm{X}$ at seven o'clock. $\times$ I 500 .

Frgs. 3 and 4 .- Metaphase II in cells with (fig. 4) and without (fig. 3 ) the $X$ to show size range of the complement. $\times{ }_{15} 00$.

FIG. 5.-Pachytene; note pre-condensation of autosomal centric ends and precocity of separation of the 3 small pairs of homologues. Positively heteropycnotic $\mathrm{X}$ at nine o'clock. $\times 900$.

Frg. 6.-Metaphase I; note arrangement of negatively heteropycnotic $\mathrm{X}$ and the three $S$ bivalents inside the hollow spindle. $\times 900$.

FIG. 7.-Anaphase I ; note lagging L2 bivalent with a chromatid-bridge. $\times \mathrm{I}_{500}$. 


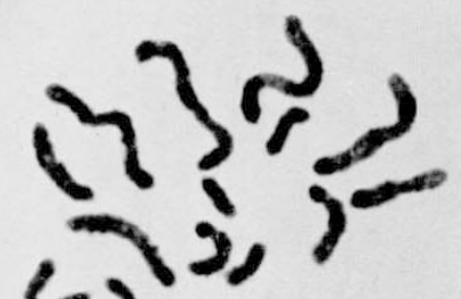

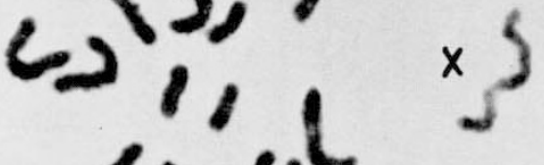

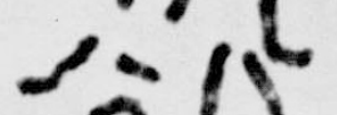

25

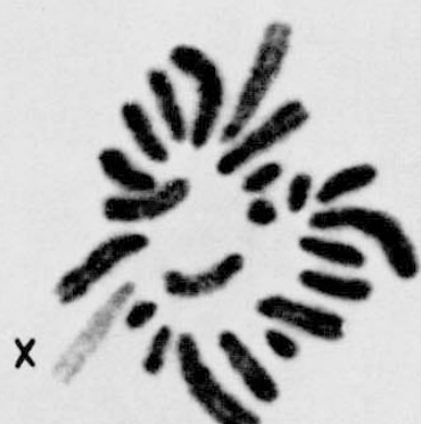

2

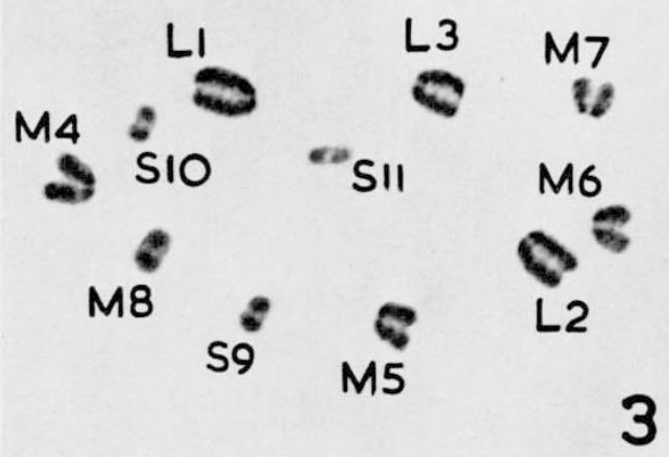

L. ${ }^{M 4}$

$$
{ }^{5}{ }^{2}{ }^{2}: e^{M 7}
$$

2

LI

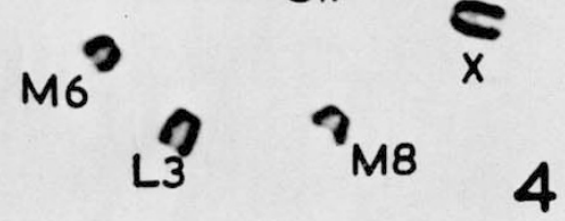

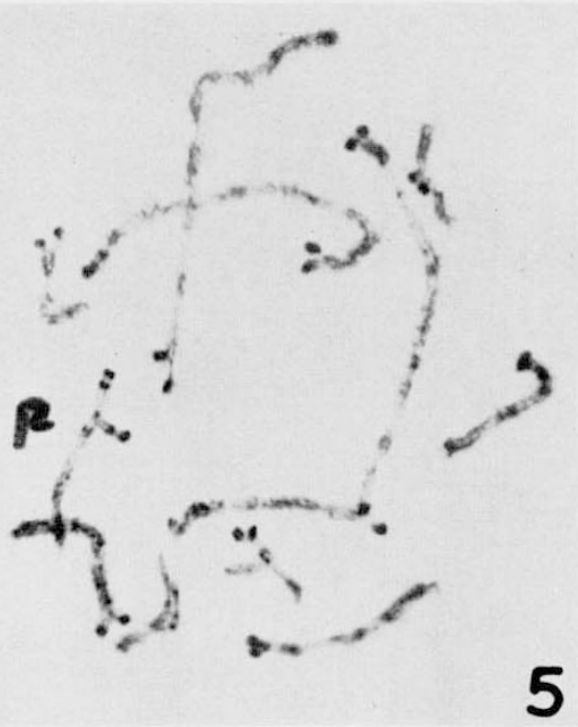

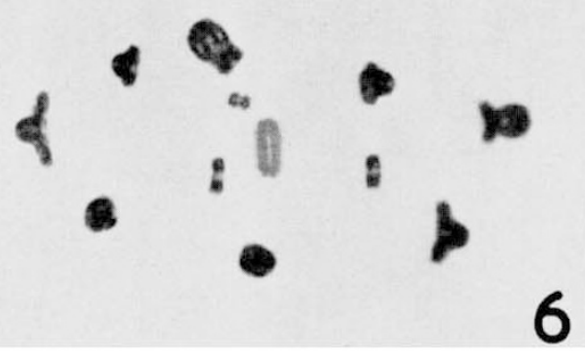

6

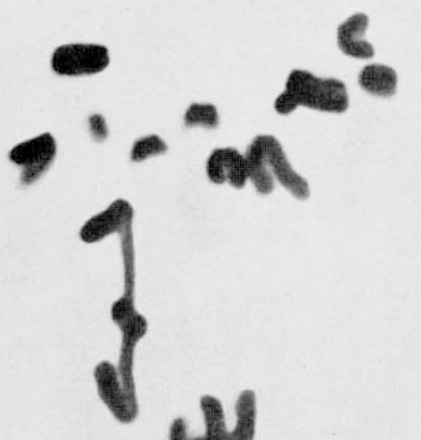

6.

4 .

6

당 


\section{Plate II}

All acetic orcein squash preparations.

Fig. 8.-Early diplotene; note pronounced heteromorphic gap in the L3 bivalent. $\times 900$.

Fig. 9.-Enlargement of the anomalous chromosome of fig. $8 . \times 275^{\circ}$.

FIG. I0.-Pachytene; note two Sio univalents at seven o'clock. $\times 900$.

FIG. I I.-Diakinesis ; note two $\mathrm{S}_{9}$ and two M8 univalents. $\times 900$.

FIG. I2.-Diakinesis; note two $S_{I} 1$ univalents. $\times 900$.

FIG. I3.-Metaphase I ; this nucleus contains an $\mathrm{L}_{3}-\mathrm{M} 8$ terminal interchange (CIII+ $1+9 \mathrm{II}+\mathrm{X})$. The interchange trivalent is in indifferent orientation.

FIG. I4.-Diakinesis; here the nucleus contains a ring-of-four multivalent (RIV $+10 I I+X)$ which is the consequence of pre-meiotic non-disjunction. $\times 900$. 

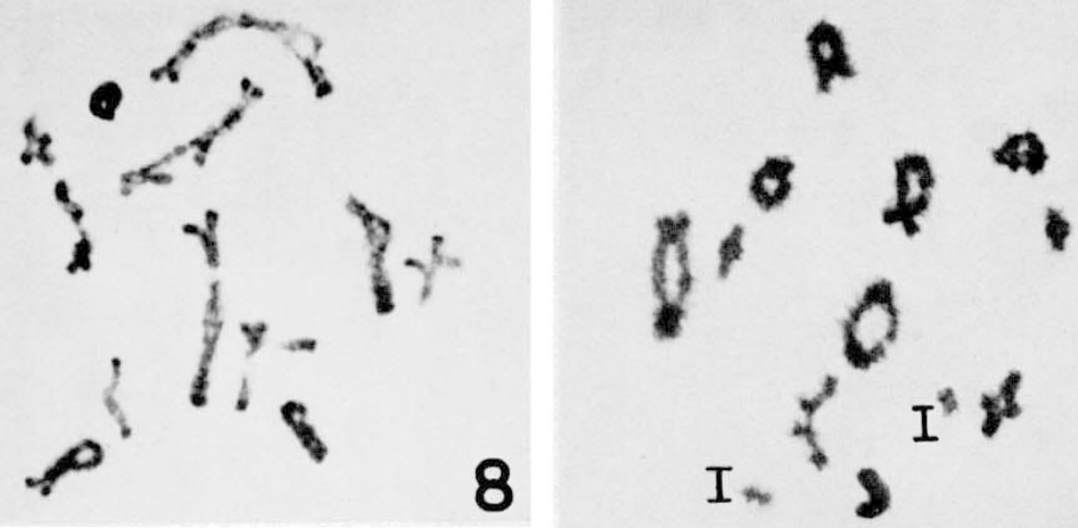

12
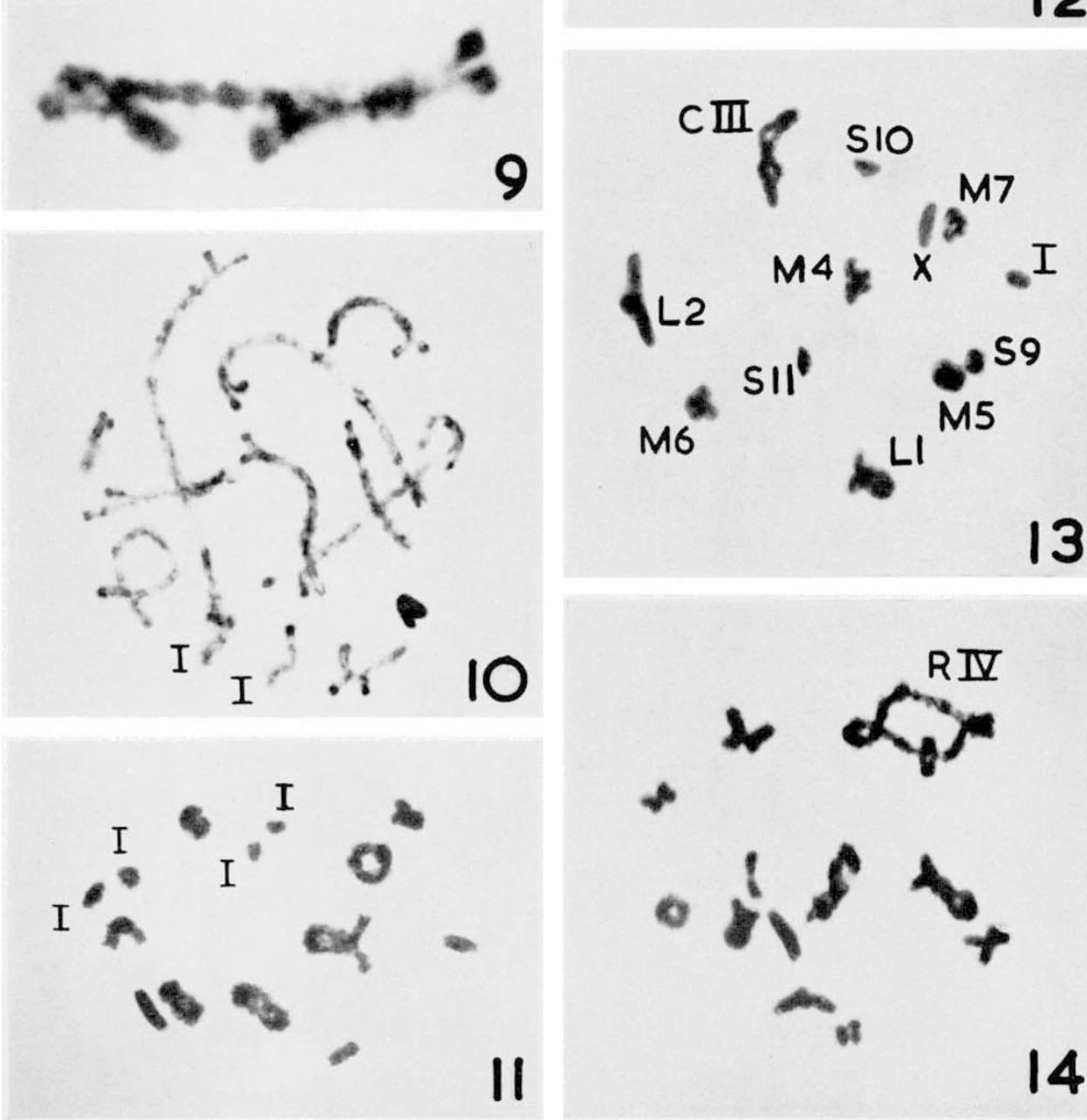

14 